\title{
Practice Guideline Development for Referral Patients with Acute Stroke at Primary Level Hospital
}

\author{
Arissara SUKWATJANEE \\ Department of Adult and Gerontology Nursing, Faculty of Nursing, Srinakharinwirot University, \\ Nakhon Nayok 26120, Thailand
}

(Corresponding author's e-mail: arissara@swu.ac.th)

Received: 31 May 2017, Revised: 11 March 2018, Accepted: 30 April 2018

\begin{abstract}
This action research aimed to develop a practice guideline for referral patients with acute stroke at a primary level hospital. Seventy two participants were healthcare providers working at an emergency room of the hospital. The participants were divided into 2 teams of developing and trying out the guideline by using the conduct and utilization of research in nursing model (CURN) as a conceptual framework. Descriptive statistics were used to assess the participants' demographic characteristics including feasibility and possibility of using the guideline among the participants. Problems and obstacles of using the guideline were analyzed via content analysis. After 12 months of developing and trying out the guideline with acute stroke patients at an emergency room, the result revealed that time spent for referral of the patients was approximately 45 min reaching the standard of the American Heart Association. The recommendation was that this effective practical guideline could benefit referral patients with acute stroke at a primary level hospital.
\end{abstract}

Keywords: Practice guideline, refer, acute stroke, primary level hospital

\section{Introduction}

Recently, 55 million people/year with stroke worldwide were found and 7.5 million/year of those died [1]. In Thailand, the Ministry of Public Health reported that stroke patients were 27,767 people/100,000 population and 176,342 people died from ischemic and hemorrhagic stroke [2]. Stroke creates physical deformity and an economic burden. Most patients experience neurological symptoms such as weakness of limbs and the problem of swallowing, speaking and walking. These symptoms are caused due to an insufficient blood supply in the patients' brain [3-5]. The important point to avoid the symptoms is that the stroke patients need to be sent to see a physician very rapidly for early treatment within $3-4.5 \mathrm{~h}$ after symptoms are found $[6,7]$.

From 2012 - 2016, there were 141 stroke patients receiving critical care service in the emergency room at Sena Hospital, the research setting of this study [8]. It was found that 2 percent of those patients died from airway obstruction, heart failure and brain death. This was due to the patients having an incomplete assessment such as an electrocardiogram (EKG) and a computerize tomography (CT), a brain scanning. The specimen testing at the laboratory room always took a long time that made them receive late medical treatment. The patients also did not receive immediate medical treatment because of having only one physician working at the emergency room and taking responsibility for other departments at the same time. The time spent for caring and referring the patients to the provincial hospital for having a brain scan, neuro-medical and neuro-surgical caring was an average of $1.50 \mathrm{~h}$ [8].

A review of the literature found that a clinical practice guideline for caring for stroke patients in the crisis stage is used in tertiary level hospitals [9]. The guideline may not be fit for dealing with patients in a primary level hospital because of different resources, medical instruments and healthcare teams. A prior 
http://wjst.wu.ac.th

research study has also stated that primary level hospitals have limit standard practice guidelines for patients' referral with acute stroke [9]. Therefore, patients have no opportunity for appropriate care. Since the standard time spent caring for stroke patients in critical care units should be not exceeded 30 min and the patients have to receive anticoagulant drugs within $60 \mathrm{~min}$ [10-14]. Thus, we had the idea to develop an effective practice guideline using the conduct and utilization of research in nursing model (CURN) [15] as a framework for patients with acute stroke at a primary level hospital such as Sena Hospital.

\section{Research objective}

The objective was to develop a practice guideline for referral patients with acute stroke at a primary level hospital.

\section{Materials and methods}

\section{Research design}

The research design was an action research to develop a practice guideline for referral patients with acute stroke in an emergency department at Sena Hospital, Ayutthaya Province, Thailand. The conceptual framework used in this study was the CURN model [15].

\section{Research setting}

The research setting, Sena Hospital, was purposive sampling since it was a primary level hospital and having no a practice guideline for referral patients with acute stroke.

\section{Participants}

Seventy two participants from Sena Hospital were purposively sampled. The criteria used to select them was they were part of the healthcare team who work at the emergency room and were willing to participate in the study. The participants were divided into 2 teams:

Team 1 consisted of the participants who developed the practice guideline comprising 30 nurses, 5 physicians, 2 pharmacists, and 2 laboratory technicians.

Team 2 consisted of the participants who tried out the practice guideline comprising 30 nurses, 1 physician, 1 pharmacist, and 1 laboratory technician.

\section{Research instruments}

1. The practice guideline and the manual for using the guideline for referral patients with acute stroke. The researcher developed the guideline from the practice guideline of the Prasat Neurological Institute [16]. The development of the guideline considered the limited resources of a primary level hospital such as Sena Hospital. The objective was to be a standard guideline for referral patients with acute stroke. For the content validity index (CVI), the practice guideline and the manual for using the guideline were sent to 3 experts who are neuro-medical and neuro-surgical physicians of Ayutthaya Hospital and the head nursing of the critical department of Siriraj Hospital. The CVI of the guideline was 0.89 .

2. The questionnaires asking the participants for opinions related to the development of the practice guideline either the initial assessment and monitoring suspected patients with transient ischemic attack (TIA) or referral patients from a primary to tertiary level hospital. The questionnaires were developed by the researcher comprising: (i) general information such as gender, age, work experience, and education level and (ii); feasibility and possibility of using the guideline in the real situations encountered in a primary level hospital.

\section{Ethical considerations}

Ethical approval was attained from Srinakharinwirot University on research ethics and the approved number was SWUEC/X-076/2014, prior to commencing the study. The directors of Sena Hospital, where the data were collected, also granted permission to conduct the study. The participants were informed 
http://wjst.wu.ac.th

about the study's purpose and voluntary participation. The confidentiality and anonymity issues were concerned during per 12 months of data collection. The records related to the personal information of participants were only accessed by the researcher and it was not be possible to match personal information of participants or with the informed consent form. The contents of the interview transcriptions will also be kept confidential in a locked place by the researcher at the office at the Faculty of Nursing, Srinakharinwirot University, Nakhon Nayok Province for 5 years before destruction. The participants have the right to withdraw from the study at any time they feel burdened or any discomfort without affecting their work. Informed consent was obtained for each participant prior to his/her participation in the study.

\section{Procedure}

The procedure was derived from the CURN model [15] which is divided into 4 stages: (i) the situation analysis related to current acute care for stroke patients, (ii) the development of the guideline for the patients, (iii) the implementation and practice trial by testing the guideline for feasibility and applicability in caring for acute stroke patients, and (iv), the evaluation of the guideline and its integration into practice change. Data collection was 12 months, between January and December 2014. The details are as follows:

Stage 1 analyzed problems of referral patients with acute stroke at Sena Hospital for 2 months.

This stage systematically explored the phenomena of stroke patients receiving care service at the emergency room of the hospital. The researcher accumulated knowledge and evidence related to problems in the points of patients, nursing care, and nursing system. The action processes were:

1. The researcher set the development team to adjust the practice guideline of referral patients with acute stroke. The directors of Sena Hospital were asked permission to collect the data.

2. The researcher scheduled 4 formal meetings to discuss previous problems such as health screening, physical assessment, symptom observation, treatment, cooperation, laboratory, and medical instrument in caring for patients with TIA/stroke and working as a care team. Other issues mentioned concerned strength and weakness, opportunity, and threat to the caring system such as the service system, nursing system, job description, and assignment.

Stage 2 developed the guideline for 3 months.

The researcher scheduled 6 formal meetings to discuss the process of conducting the guideline following the CURN model [15] as follows:

1. Defined the group of patients with acute stroke.

2. Stated objectives and outcomes to develop the guideline.

3. Plotted the practice guideline.

4. Outlined the current information related to referral patients with acute stroke from previous research studies.

5. Discussed with the development team using the developed guideline and conducted a manual of the guideline. The manual comprised: (i) objectives and definition of the stroke patients in criteria for using the guideline, (ii) diagram of the guideline, (iii) record forms, and (iv), content of the guideline.

6. Conducted questionnaires to assess effectiveness of using the guideline that composed of: (i) demographic data of the healthcare team who used the guideline and (ii) feasibility and possibility of using the guideline.

7. The practice guideline was assessed for appropriate and inappropriate content with a validity index (CVI) by 3 experts who are neuro-medical and neuro-surgical physicians at Ayutthaya Hospital and the head nurse of the critical department at Siriraj Hospital. The CVI of the guideline of this study was 0.89 that reached the standard CVI of at least 0.8 [17].

Stage 3 Try out the guideline for 6 months.

This stage used the developed practice guideline on patients with acute stroke in the emergency room at Sena hospital. The details were as follows: 
1. The researcher set the try out team to use the developed guideline in the emergency room at the hospital for 6 months. During the tryout period, the researcher's team gathered information on problems and obstacles of using the guideline to protect patients and participants, and provided advice if something went wrong.

2. The developed and try out teams conducted 12 formal meetings discussing problems and the way to improve any obstacle in using the developed guideline.

Stage 4 Evaluate the guideline for one month.

This stage was the evaluation the guideline by the developed and try out teams. Each participant evaluated the way of using the guideline in the emergency room. The details of evaluation were as follows:

1. Evaluated the suitability of using the guideline and shared opinions about the strengths and weakness, risks and benefits.

2. Assessed the patient outcomes through time to service following the standard of caring for stroke patients [11-14].

3. Discussed the opinions, recommendations, and probability of using the guideline.

4. The researcher presented the guideline to the directors of Sena Hospital for improving caring and referral of stroke patients. In this step, there was a meeting to make a commitment among the participants related to job description and other processes. Besides, attending and clarifying some additional problems were solved continuously.

\section{Statistical analysis}

Descriptive statistics were used to assess the samples' demographic characteristics including feasibility and possibility scores of using the guideline among nurses in the emergency room at Sena Hospital. Problems and obstacles of using the guideline were analyzed via content analysis.

\section{Results and discussion}

\section{Demographic data among participants}

The participants were mostly female $(n=65 ; 90.28 \%$ ); and between 26 to 45 years of age (average 32.5 years old); and all persons were educated at the bachelor level. Those nurses had work experience in the emergency room between 3 to more than 10 years (average 8.75 years), Table 1 .

Table 1 Demographic data among participants $(n=72)$.

\begin{tabular}{ccc}
\hline \multicolumn{1}{c}{ Demographic data } & Frequency & Percentage \\
\hline Gender & 7 & 9.72 \\
Male & 65 & 90.28 \\
Female & & 19.44 \\
Age $($ year) & 14 & 40.28 \\
$20-30$ & 29 & 40.28 \\
$31-40$ & 29 & 100.00 \\
$41-50 \quad$ Mean $=32.50$, Min-Max $=26-45, \mathrm{SD}=5.64$ & & 9.72 \\
Educational level & 72 & 50.00 \\
Bachelor degree & & 40.28 \\
Work experience in emergency department (year) & 7 & 36 \\
$0-5 \quad 29$ & 29 \\
$6-10 \quad$ Mean $=8.75$, Min-Max $=3-10, \mathrm{SD}=7.57$ & & \\
$>10 \quad$ & & \\
\hline
\end{tabular}




\section{Demographic data among patients with acute stroke at Sena Hospital}

Table 2 presents the general information of 61 patients with acute stroke receiving care and referral service at the emergency room at Sena Hospital between January 1 and October 31, 2014. The patients were mostly female $(n=37 ; 60.66 \%)$. The $39.35 \%$ of them were aged between 51 and 60 years, with an average age of 52.20 years. All patients were conscious with a Glasgow Coma Scale (GSC) between 13 and 15 and had a problem of speaking and weakness in their arms and legs. The $45.90 \%$ of the patients were referred to Ayutthaya Hospital, Ayutthaya Province.

Table 2 Demographic data among stroke patients $(n=61)$.

\begin{tabular}{lcc}
\hline \multicolumn{1}{c}{ Demographic data } & Frequency & Percentage \\
\hline Gender & & \\
Male & 24 & 39.34 \\
Female & 37 & 60.66 \\
Age (year) & & \\
$\quad 30-40$ & 17 & 27.86 \\
$41-50$ & 20 & 32.79 \\
$51-60 \quad 24$ & 39.35 \\
$\quad$ Mean = 52.20, Min-Max =31 - 58, SD =4.31 & & \\
Symptoms & 61 & 100.00 \\
GCS 13 - 15 scores & 61 & 100.00 \\
Problem of speaking, weakness of limbs & & \\
Treatment Outcome & 28 & 45.90 \\
Refer & 33 & 54.10 \\
Admit & & \\
\hline
\end{tabular}

Table 3 Assessment and probability of using the guideline $(n=30)$.

\begin{tabular}{lccc}
\hline \multicolumn{1}{c}{ Section } & $\begin{array}{c}\text { Difficult } \\
\text { Frequency (\%) }\end{array}$ & $\begin{array}{c}\text { Easy } \\
\text { Frequency (\%) }\end{array}$ & $\begin{array}{c}\text { Probability } \\
\text { Frequency (\%) }\end{array}$ \\
\hline 1. Screening and asking history & - & $30(100.00)$ & $30(100.00)$ \\
2. Assessing and caring in acute stage & $6(19.44)$ & $24(80.56)$ & $30(100.00)$ \\
3. Neurological examination & $9(30.56)$ & $21(69.44)$ & $24(80.56)$ \\
4. Laboratory examination & - & $30(100.00)$ & $30(100.00)$ \\
5. Special examination & - & $30(100.00)$ & $30(100.00)$ \\
6. Guideline to notify the physician & - & $30(100.00)$ & $30(100.00)$ \\
7. Physician treatment & - & $30(100.00)$ & $30(100.00)$ \\
8. Assessment for symptom awareness & $3(9.72)$ & $27(90.28)$ & $30(100.00)$ \\
9. Providing information to patients & - & $30(100.00)$ & $30(100.00)$ \\
10. Referring the patients & $12(40.28)$ & $18(59.72)$ & $21(69.44)$ \\
\hline
\end{tabular}




\section{Develop and try out of using the guideline}

All participants in the try out team stated it was easy to conduct the patients' health screening and history of illness, laboratory and special examination, method to notify the physician, and providing information to patients and their relatives. The $90.28 \%$ of them specifically said that the assessment for symptom awareness was easy to use. However, $40.28 \%$ of them complained that referring the patients was a hard job because there was no relative to give the patient's information, and they were unable to clear the heavy traffic flow, especially in this urban area. The $30.56 \%$ of them mentioned the difficulty to take the neurological examination, especially motor power. The $19.44 \%$ of the participants commented on the fact that assessing and caring for the patients in acute stage was hard to do in a short period of time, Table 3.

\section{Evaluation of using the guideline}

Time spending in caring and referral the patients

The time spent for caring and referral patients with acute stroke took $45 \mathrm{~min}$ from getting initial care to referral, Table 4.

Table 4 Time spend regarding activities from getting initial care to referral $(\mathrm{n}=61)$.

\begin{tabular}{|c|c|c|}
\hline Activities & $\begin{array}{l}\text { Standard time } \\
\text { (minutes) }\end{array}$ & $\begin{array}{l}\text { Practice time } \\
\text { (minutes) }\end{array}$ \\
\hline 1. Ask information of illness, EKG, assess vital sign, initial care & 10.00 & 7.80 \\
\hline 2. Notify a physician & 10.00 & 6.40 \\
\hline 3. Physical assessment by a physician, laboratory analysis, and diagnosis & 15.00 & 11.30 \\
\hline 4. Refer & 30.00 & 25.20 \\
\hline Total & 65.00 & 45.00 \\
\hline
\end{tabular}

The practice guideline for referral patients with acute stroke

The practice guideline for referral patients with acute stroke for this study is shown in Figure 1. In the initial period, an ER nurse screened the patients whether they had 1 in 5 symptoms or more such as limb weakness, problem of speaking, dizziness, loss of visual sight, and severe headache. The nurse then asked for the presence of illness and the time of the onset of symptoms. She also checked vital signs and neuro-signs, and notified the physician. After the physician had assessed through a physical examination, he treated the crisis symptom with medication prepared by a pharmacist. In the final period a document was prepared, an ER nurse, an ambulance, and referral of the patient to a tertiary level hospital. The total time spent for caring and referral the patient from the initial until final period was $45 \mathrm{~min}$. 


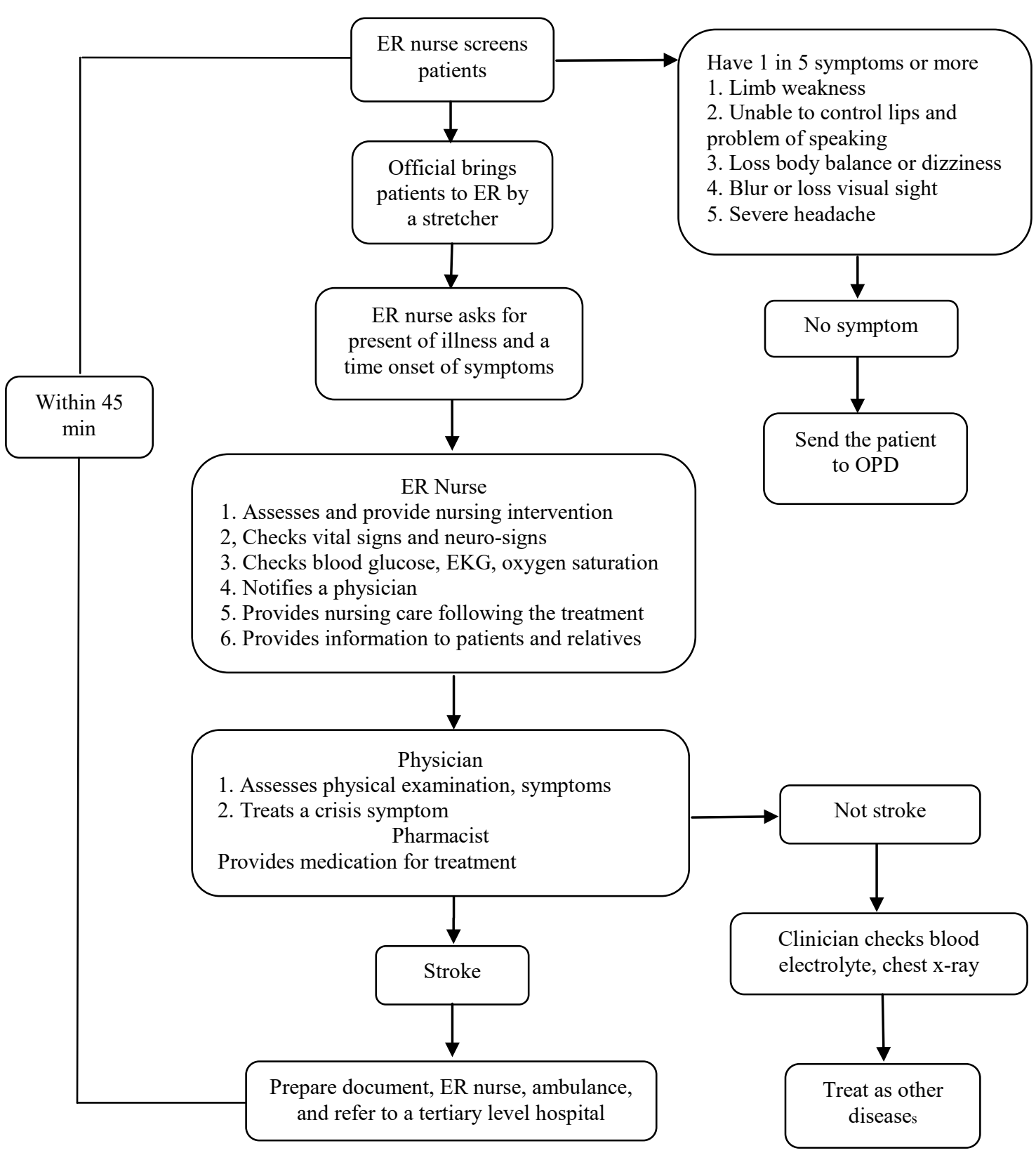

Figure 1 The practice guideline for referral patients with acute stroke.

Problems and obstacles of using the guideline

From the content analysis through in-depth interview nurses who used the guideline, it was found that they did not check the EKG of the patients because some physicians did not request it, even the standard of caring need [3,11]. The referral process was slow because of the long time spent for treatment, laboratory, and the patients' relative. Other obstacles were the inconvenient transportation and the limitation of patients' beds at the province hospital. 


\section{Discussion}

The findings are discussed in 5 points as follows:

1. The conceptual framework used in the study. The CURN model was used as a conceptual framework to develop the practice guideline for referral patients with acute stroke through the process of criticizing problems, problem-solving, and evaluating, systematically [15]. The developed guideline focused on patients and the caring system cooperating with therapeutics for the purpose of possessiveness. This idea related to the opinion of Grol [18] who stated a good way to solve problems was bringing everyone to participate for the purpose of possessiveness in order to be sustainable.

2. The development of the practice guideline. The guideline of this study was derived from the guidelines of the Prasat Neurological Institute [12]. The content in the guideline was adjusted to fit the context of a primary level hospital. This was congruent to the study of Thongchai and Nuntachaipun [19] that the development team should adjusted the guidelines to fit to the context of the stroke care and test for effectiveness before conducting data.

3. The initial assessments. For the conflict about whether every patient has to receive the EKG, the agreement was that all patients need to have it for the purpose of making a decision related to medication used. Some blood testes such as complete blood count (CBC), electrolyte, urea nitrogen and creatinine, always take time. The commitment of the development team allowed the patients referral to another hospital first and then the blood tests were sent to the hospital later.

4. The evaluation of using the developed guideline. All participants stated the ease of conducting the developed guideline such as screening and asking for history of illness, laboratory and special examination, method to report the physician, and providing information to patients and relatives. It can be explained that those participants had developed the guideline, in doing so, everyone understood the content in it. However, with the limit of time for caring the patients, some participants complained about incomplete caring of the patients during admission in the emergency room. For example, they have no time for tepid sponge the patients in order to decrease their fever. Someone mentioned the difficulty to take the neuroscience examination, especially muscle power. Because the patients were unconscious, it was likely hard to differentiate the muscle power at that time. Besides, it was difficult to find the patients' relatives in the crisis time because the persons who brought the patients to the hospital were other people. At this point, the development team agreed to transfer the patients before contacting their family members.

5. The referral time spending. Time spent for referral the patient with acute stroke was approximately 45 minutes. This outcome conforms to the standard of caring stroke patients of the American Heart Association [13]. Having the standard guideline also facilitates nurses in making decisions for caring. The results are similar to the study of Considine and McGillivry [20] that explored the effectiveness of a practice guideline for caring stroke patients in an emergency department. They found the guideline encouraged the screening, increased decision of the symptom assessment, and risk management. Moreover, the finding presented a positive outcome of service and increased satisfaction among patients and their relatives.

\section{Conclusions}

The study aimed to develop the practice guideline for referral patients with acute stroke in a primary level hospital. The guideline was tried out by the healthcare team and showed the effectiveness in its use. Time spent for referral of the patient was approximately $45 \mathrm{~min}$ reaching the standard of the American Heart Association [13]. The limitation is that testing effectiveness of the guideline is not experimental research. Since the study conducted the development and try out of the practice guideline for referral patients with acute stroke, therefore, it is difficult to control the healthcare team in caring for the patients 
http://wjst.wu.ac.th

in the crisis stage. Recommendations for further study are that a practice guideline should be developed for caring patients in other crisis stages such as diabetic patients with hypoglycemia or hyperglycemia.

\section{Acknowledgements}

The study was financially supported from the Faculty of Nursing, Srinakharinwirot University.

\section{References}

[1] EM Barker. Neuroscience Nursing: A Spectrum of Care. $3^{\text {rd }}$ eds. Mosby Elsevier, St. Louis, Mo, 2008, p. 521-63.

[2] Ministry of Public Health, Available at: http://www.moph.go.th, accessed March 2018

[3] WJ Powers, AA Rabinstein, T Ackerson, OM Adeoye, NC Bambakidis and K Becker. 2018 guidelines for the early management of patients with acute ischemic stroke: A guideline for healthcare professionals from the American Heart Association/American Stroke Association. Stroke $2018 ; 49$, e46110.

[4] LP Kammersgaard, HS Jorgensen, JA Rungby, J Reith, H, Nakayama and UJ Weber. Admission body temperature predicts long-term mortality after stroke: The copenhagen stroke study. Stroke 2002; 33, 1759-62.

[5] MW Parsons, A Barber, PM Desmond, TA Baird, DG Darby and G Bymes. Acute hyperglycemia adversely affects stroke outcome: A magnetic resonance imaging and spectroscopy study. Ann. Neurol. 2002; 52, 20-8.

[6] W Hacke, G Donnan, C Fieschi, M Kaste, JP Broderick and T Brott. Association of outcome with early stroke treatment: Pooled analysis of ATLANTIS, ECASS, and NINDS rt-PA stroke trials. Lancet 2004; 363, 768-74.

[7] C Lu-Emerson, D Likosky, A Amin and D Tirschwell. Management of ischemic stroke: Part I emergency room management. J. Hosp. Med. 2010; 5, 33-40.

[8] Sena Hospital. Patient file 2012-2016 (in Thai). Sena Hospital, Ayutthaya Province, 2012.

[9] S Theamkao. Development of stroke network in north-east part (in Thai). J. Thai Stroke Soc. 2015; 14, 3-13.

[10] C Koosuwan, W Hankunakun and S Sirikun. Development of continuing care in stroke patients at Nopparut Radchatanee (in Thai). In: Proceedings of the Human Source and Service with Human Heart. 2009.

[11] American Heart Association. Guidelines for cardiopulmonary resuscitation and emergency cardiovascular care. Circulation 2015, 132, S315-67.

[12] National Collaborating Centre for Chronic Conditions (UK). Stroke: National Clinical Guideline for Diagnosis and Initial Management of Acute Stroke and Transient Ischemic Attack (TIA). Available at: https://www.ncbi.nlm.nih.gov/pubmed/21698846, accessed March 2018.

[13] DR Summers, A Leonard, D Wentworth, JL Saver, J Simpson and JA Spilker. Comprehensive overview of nursing and interdisciplinary care of the acute ischemic stroke patient: A scientific statement from the American Heart Association. Stroke 2009; 40, 2911-44.

[14] EC Jauch, JL Saver, HP Adams, A Bruno, JJ Connors and BM Demaerschalk. Guidelines for the early management of patients with acute ischemic stroke. Stroke. 2013; 44, 870-947.

[15] JA Horsley, J Crane, MK Crabtree and DJ Woos. Using research to Improve Nursing Practice: A Guide (CURN Project). Grune \& Stratton, Orlando FL, 1983, p. 33-5.

[16] Prasat Neurological Institute. Guideline of Caring Stroke Patients for General Nurses (in Thai). Neuroscience Institute, Medical Center, Ministry of Public Health, Bangkok, 2011, p. 26-9.

[17] P Ponprasert. Development of Nursing Guideline for Discharge Planning in Patients Retained Central Vein Catheter (in Thai). MNS Thesis, Prince of Songkla University, Songkla, Thailand, 2009.

[18] R Grol. Beliefs and evidence in changing clinical practice. BMJ 2006; 332, 151. 
http://wjst.wu.ac.th

[19] C Thongchai and P Nuntachaipun. Opinion survey related to use a practice guideline (in Thai). In: Proceedings of the Evidence Based Practice. Faculty of Medicine, Chiang Mai University, Chiang Mai, Thailand, 2004.

[20] J Considine and B McGillivry. An evidence-based practice approach to improve nursing care of acute stroke in an Australian emergency department. J. Clin. Nurs. 2010; 19, 138-44. 